Rev. Adm. Saúde (On-line), São Paulo, v. 20, n. 78: e203, jan. - mar. 2020, Epub 10 fev. 2020 http://dx.doi.org/10.23973/ras.78.203

RELATO DE CASO

\title{
Aplicação dos elementos de planejamento estratégico para estruturação de uma divisão de farmácia hospitalar
}

\author{
Application of strategic planning elements for structuring the hospital \\ pharmacy division
}

\section{Vanessa D’amaro Juodinis ${ }^{1}$, Ana Paula Callejo de Souza², Altamir Benedito de Sousa ${ }^{3}$}

1. Graduada em farmácia, residência em farmácia clínica e atenção farmacêutica. Residente do Hospital Universitário da USP (HU-USP), São Paulo SP

2. Graduada em farmácia, especialista em qualidade e produtividade. Farmacêutica chefe do Serviço de Farmácia Hospitalar da Divisão de Farmácia do HU-USP, São Paulo SP

3. Graduado em farmácia, doutor em farmácia. Farmacêutico da Divisão de Farmácia do HUUSP, São Paulo SP

\section{RESUMO}

A assistência farmacêutica vivencia um panorama de busca por maior eficiência e segurança no processo de utilização do medicamento o qual se inicia com o conhecimento dos elementos que compõem o planejamento estratégico organizado nas seguintes etapas: determinação de quem somos, ou seja, nossa missão, após o estabelecimento de como estamos, por meio da análise ambiental, em seguida do que queremos, ou seja, nossos objetivos. A análise ambiental trata da realização do diagnóstico onde são analisados os ambientes externo e interno do serviço por meio de um estudo onde são coletadas informações referentes às ameaças e as oportunidades existentes no ambiente em que a organização está inserida com a finalidade de evitar situações desvantajosas e aproveitar os aspectos favoráveis. Depois de determinadas as oportunidades e as ameaças, é possível confrontar essas informações com as forças e as fraquezas da organização por meio da matriz SWOT. A aplicação desta ferramenta ocorre por meio da análise destes pontos 
em quatro dimensões: alavancas, defesas, limitações e problemas. Desta forma, a aplicação desta ferramenta permite o desenvolvimento de um planejamento das atividades de um setor ou serviço de maneira mais ágil, assertiva, objetiva e integrada ao potencial da instituição, dos colaboradores e do ambiente. O objetivo deste estudo foi de estabelecer como estamos para contribuir com o aprimoramento do planejamento estratégico dentro da Divisão de Farmácia do Hospital Universitário da Universidade de São Paulo com a finalidade de promover melhorias futuras no setor baseadas na missão do serviço. Trata-se de um estudo de natureza exploratória, descritiva e qualitativa, que utilizou as ideias apresentadas, ou brainstorming, pelos colaboradores para realizar o diagnóstico dos ambientes interno e externo. Ao final pode-se observar que o objetivo pretendido foi alcançado, uma vez que a aplicação da ferramenta permitiu o levantamento de informações que contribuíram com o aprimoramento do planejamento estratégico dentro da divisão de farmácia e possibilitou uma reflexão entre os colaboradores referente as problemáticas e potencialidades do serviço.

Palavras-chave: planejamento estratégico; matriz SWOT; farmácia hospitalar.

\begin{abstract}
Pharmaceutical assistance has been seeking for greater efficiency and safety in the process of drug use that begins with the knowledge of the elements that make up the strategic planning in the following stages: determination of who we are, that is, our mission, after analyzing how we are and then set our goals. The analyses of how we are is done through a study where information is collected about the threats and the opportunities existing in the environment in which the organization is inserted and the strengths and the weaknesses in the workplace. The threats and opportunities can be crossed with the strengths and the weaknesses through the Swot Matrix. The application of this tool results in four dimensions: levers, defenses, limitations and problems. Thus, the application of this tool allows the development of strategic planning more agile, assertive, objective and integrated to the institution's potential, the employees' potential and the environment's potential. The aim of this study was to establish how we are to contribute to the improvement of the strategic planning within the Pharmacy Division of the University Hospital of the University of São Paulo in order to promote mission-based division improvements. This was an exploratory, descriptive and qualitative study that used the ideas presented by employees during a brainstorming to make the diagnosis. At the end it can be observed that the intend objective was achieved because the application of the tool enabled the gathering of information and reflection of the collaborators regarding the problems and potentialities of the Pharmacy Division.
\end{abstract}

Keywords: strategic planning; SWOT matrix; hospital pharmacy 


\section{INTRODUÇÃO}

A assistência farmacêutica vivencia um panorama de busca por maior eficiência e segurança no processo de utilização do medicamento. Este panorama contrapõe o contexto em que as instituições públicas vivenciam: de limitações de recursos, de aumento da demanda de pacientes no Sistema Único de Saúde (SUS), da falta de organização no fluxo de atendimento do SUS, do excesso de burocracia, da dificuldade de lidar com mudanças principalmente advindas do meio externo e do aumento do fluxo de informações. Estas condições tornam um desafio para este setor: a melhoria da qualidade dos processos que devem estar alinhados com a estratégia planejada pelo serviço e as necessidades do cliente. ${ }^{1,2,3}$

O movimento da qualidade em saúde ganhou espaço bem depois da área industrial e se diferencia dos outros prestadores de serviços por ser o ser humano enfermo o cliente que deve passar por uma série de processos complexos e interligados dentro de um hospital para permitir sua saída com saúde. O cliente/ paciente tem dificuldade de distinguir o atendimento de boa ou má qualidade, pois as atividades desenvolvidas dentro do ambiente hospitalar carregam um potencial de dano implícito. Além disso, possui uma estrutura física complexa com muitas configurações espaciais, diversos profissionais de diferentes áreas com diferentes atuações tendo que atuar em conjunto com o mesmo propósito e objetivo. Os ambientes externos que envolvem a instituição são diversificados como órgãos de controle e fiscalização além dos fornecedores de diferentes insumos que compõem a cadeia de suprimentos da organização. ${ }^{3,4}$

O caminho para a busca da qualidade se inicia com o conhecimento dos elementos que compõem o planejamento estratégico que segundo Valadares (2002) ${ }^{5}$ podem ser organizados nas seguintes etapas: determinação de quem somos, ou seja, nossa missão, após o estabelecimento de como estamos por meio da análise ambiental, em seguida do que queremos, ou seja, nossos objetivos. As etapas posteriores constituem em como atingir nossos objetivos e mensurar nosso desempenho. A missão é descrita como a razão de existir de uma organização, sua função é direcionar e inspirar as pessoas a caminhar em direção aos propósitos do serviço em todos os níveis hierárquicos e deve refletir a essência do negócio. ${ }^{6} \mathrm{~A}$ visão de futuro é descrita como o que a organização deseja conseguir, onde deseja chegar e estabelece um sentido para a instituição, devendo inspirar quais ações deverão ser tomadas no presente para que se conquiste o futuro desejado. ${ }^{7}$

A análise ambiental trata da realização do diagnóstico onde são analisados os ambientes externo e interno do serviço por meio de um estudo onde são coletadas informações referente as ameaças e as oportunidades existentes no ambiente em que a organização está inserida com a finalidade de evitar situações desvantajosas e aproveitar os aspectos favoráveis. ${ }^{8} \mathrm{O}$ ambiente externo é o espaço onde o serviço está inserido e não possui controle e este pode ser dividido em macroambiente e ambiente setorial. ${ }^{6,9} \mathrm{O}$ macroambiente é constituído por variáveis consideradas gerais, que não afetam exclusivamente 
o setor em estudo como os aspectos econômicos, políticos, sociais, tecnológicos, legais e outros. Estes fatores estão fora do controle da organização e podem causar grandes impactos no planejamento do setor. .,10 $^{9}$ Quando se refere a fatores que são diretamente ligados ao serviço, mas ainda não há controle total sobre eles, têm-se o ambiente externo setorial onde são considerados os clientes, fornecedores, agências reguladoras, negócios que atuem no mesmo âmbito. ${ }^{9}$ No estudo do ambiente interno são consideradas as competências e atuais recursos do serviço e são analisadas as maiores forças e as fraquezas do setor para assim entender quais recursos podem ser aproveitados e quais devem ser melhores desenvolvidos. ${ }^{8,9,10}$ No ambiente interno os pontos fortes são as variáveis positivas que são controladas pela organização ou serviço, ou seja, é aquilo que desempenha da melhor forma e o diferencia no ambiente em que atua e o favorecem perante as oportunidades e ameaças oferecidas pelo ambiente externo. As fraquezas são variáveis negativas que são controladas pela organização, mas afetam seu desempenho de maneira desfavorável frente às oportunidades e às ameaças oferecidas pelo ambiente externo e, assim, requerem a aplicação dos recursos disponíveis para corrigi-los. ${ }^{8,9}$ Quando é realizada análise do ambiente interno deve-se considerar alguns tópicos: recursos humanos, comunicação, tecnologia, organização estrutural, gestão e outros que se adequarem as especificidades do serviço. Estes componentes são mais visíveis e controláveis quando comparados aos do ambiente externo. Entretanto, sempre devem ser observados os recursos disponíveis para modificar esses componentes. ${ }^{10}$

Depois de determinadas as oportunidades e as ameaças, é possível confrontar essas informações com as forças e as fraquezas da organização por meio da matriz SWOT. ${ }^{8,10}$ A aplicação desta ferramenta ocorre por meio da análise destes pontos em quatro dimensões: alavancas, defesas, limitações e problemas. A dimensão considerada favorável é a alavanca, e nela são utilizados os pontos fortes da instituição e as oportunidades oferecidas pelo ambiente externo. Quando se tem pontos fortes, porém o ambiente externo oferece ameaças tem-se a dimensão das defesas e os pontos fortes devem ser utilizados para amenizá-las. As limitações se dão quando os pontos fracos não permitem que as oportunidades oferecidas pelo ambiente externo sejam aproveitadas. A dimensão de problemas se dá quando se está diante dos pontos fracos e estes se relacionam com as ameaças oferecidas pelo ambiente externo sendo que pouco é possível fazer nesta dimensão.

Desta forma, a aplicação desta ferramenta permite o desenvolvimento de um planejamento das atividades de um setor ou serviço de maneira mais ágil, assertiva, objetiva e integrada ao potencial da instituição, dos colaboradores e do ambiente. O objetivo deste estudo foi o e estabelecer como estamos para contribuir com o aprimoramento do planejamento estratégico dentro da Divisão de Farmácia do Hospital Universitário da Universidade de São Paulo (HU-USP) com a finalidade de promover melhorias futuras no setor baseadas na missão do serviço. 


\section{MATERIAL E MÉTODOS}

Trata-se de um estudo de natureza exploratória, descritiva e qualitativa, que utilizou as ideias apresentadas, ou brainstorming pelos colaboradores de uma divisão de farmácia de um hospital universitário para realizar o diagnóstico dos ambientes interno e externo por meio da análise SWOT com a finalidade de alinhar e prosseguir com as etapas do planejamento estratégico da divisão.

Primeiramente foram realizadas oficinas junto aos colaboradores e residentes de farmácia onde foi feita uma explanação referente ao que se tratava o brainstorming e, em seguida, a ferramenta foi aplicada e opiniões coletadas referentes aos pontos fortes e fracos da Divisão de Farmácia e sobre as oportunidades e ameaças externas que poderiam influenciar na execução e qualidade dos serviços prestados pela divisão. As ideias foram registradas pelo mediador do brainstorming em planilhas previamente confeccionada (Anexo 1) com os diferentes aspectos do ambiente interno e externo para facilitar a compreensão do tema.

Após finalização das oficinas, todos os pontos fortes e fracos do ambiente interno, ameaças e oportunidades do ambiente externo foram organizados em tabelas. Neste momento, ideias duplicadas em diferentes oficinas foram unificadas e pontos que remetessem a questões interpessoais e não aos processos, a gestão ou a instituição foram retirados.

Por último, cruzaram-se os dados obtidos em quatro dimensões: alavanca, que se trata do cruzamento dos pontos forte com as oportunidades; limitações, que compreende o cruzamento das oportunidades e pontos fracos; defesa abrangendo o cruzamento dos pontos fortes e ameaças e problemas que resulta do cruzamento entre ameaças e pontos fracos.

\section{RESULTADOS E DISCUSSÃO}

A Divisão de Farmácia do Hospital Universitário da USP possui como missão "promover ensino e pesquisa de excelência, oferecendo assistência farmacêutica de qualidade ao paciente integrada à equipe de saúde" e como visão "ser referência na prática da farmácia clínica e hospitalar, comprometida com o ensino e a pesquisa e respeitada pela qualidade dos serviços prestados". A partir destes pontos do planejamento estratégico já existentes, partiu-se para a análise de suas forças e fraquezas e verificação do impacto das oportunidades e ameaças externas na construção dos objetivos estratégicos para que a missão continue a ser cumprida e a visão seja alcançada.

\section{Oficinas}

Foram realizadas 6 oficinas em períodos e dias diferentes para que se abrangesse os funcionários dos turnos da manhã, tarde e noite, nas quais participaram 32 colaboradores que puderem expor suas ideias que foram 
anotadas por um mediador e organizadas em tabelas excluindo-se as ideias que estavam duplicadas e as que se tratavam de questões interpessoais.

A Tabela 1 mostra as ideias referentes a percepção dos funcionários das oportunidades e ameaças relativas ao ambiente externo relacionadas à política da universidade, aos recursos financeiros e orçamentários, ao social, à legislação, ao SUS e à tecnologia. Referente às políticas da universidade foram ressaltadas como oportunidade o fato de o hospital estar inserido em um ambiente de ensino onde pode-se desempenhar atividades de hospital-escola ao mesmo tempo que se observa como ameaça a falta de percepção de algumas unidades na importância do desempenho destas atividades por um hospital. A crise econômica da universidade assim como as mudanças cíclicas da reitoria e consequentemente da superintendência do hospital foram colocadas como oportunidades e ameaças, pois podem influenciar de forma positiva ou negativa na gestão do hospital. A autonomia administrativa e financeira foi considerada uma oportunidade dentro do quesito recursos financeiros e orçamentários, porém a crescente demanda do SUS tanto em número de pacientes quanto na complexidade do atendimento tem tornado incompatível o orçamento disponível com os recursos necessários ao atendimento. Por outro lado, no que tange ao aspecto social, a complexidade do atendimento assim como a alta vulnerabilidade da população que vivencia um crescente envelhecimento exige uma maior interação e melhor comunicação entre as equipes multidisciplinares do hospital assim como iniciativas de humanização dos processos de cuidado ao paciente. A lei de licitações foi citada como oportunidade e ameaça no aspecto legal, já que ao mesmo tempo em que oferece barreiras burocráticas que limitam o número de fornecedores, também possibilita a aquisição apenas de medicamentos dentro das especificações de qualidade exigidas pela legislação. No que tange ao componente de tecnologia, observa-se a diversidade de tecnologias em saúde disponíveis no mercado que garantem oportunidades de melhorias na informatização dos processos assim como na segurança dos cuidados ao paciente.

Tabela 1. Análise das oportunidades e ameaças do ambiente externo Macroambiente da Divisão de Farmácia do HU-USP.

\begin{tabular}{|c|c|c|}
\hline & Oportunidades & Ameaças \\
\hline $\begin{array}{l}\text { Política } \\
\text { Universidade }\end{array}$ & $\begin{array}{l}\text { Configuração de Hospital Escola } \\
\text { inserido dentro na Universidade de } \\
\text { São Paulo } \\
\text { Mudanças nos mandatos da reitoria }\end{array}$ & $\begin{array}{l}\text { Não percepção do Hospital } \\
\text { Universitário como um polo de } \\
\text { ensino, pesquisa e extensão por } \\
\text { alguns setores da Universidade } \\
\text { Crise econômica e financeira que } \\
\text { se reflete na Universidade e na } \\
\text { falta de recursos para } \\
\text { investimentos e melhorias } \\
\text { Mudancas nos mandatos da }\end{array}$ \\
\hline
\end{tabular}


reitoria

\begin{tabular}{ll}
\hline Recursos & Universidade é uma autarquia \\
Financeiros e & possuindo autonomia administrativa \\
orçamentários & e financeira quando comparada a \\
& outros hospitais do SUS
\end{tabular}

Aumento da demanda do SUS e

da complexidade nos casos atendidos

Financiamento disponível é incompatível com a demanda de custo

\begin{tabular}{|c|c|c|}
\hline Social & $\begin{array}{l}\text { Aumento da complexidade da } \\
\text { população atendida propiciando } \\
\text { melhores casos clínicos para o } \\
\text { desenvolvimento de ensino e } \\
\text { pesquisa interdisciplinares e } \\
\text { iniciativas de humanização }\end{array}$ & $\begin{array}{l}\text { Dificuldade em conciliar o tripé } \\
\text { assistência, ensino e pesquisa } \\
\text { com o novo perfil de população } \\
\text { atendida }\end{array}$ \\
\hline Legal/SUS & $\begin{array}{l}\text { Melhoria de infraestrutura devido as } \\
\text { exigências legais da qualidade e } \\
\text { princípios norteadores do SUS } \\
\text { Lei de licitações possibilitando } \\
\text { somente a compra de fornecedores } \\
\text { que possuam especificações de } \\
\text { qualidade }\end{array}$ & $\begin{array}{l}\text { Barreiras burocráticas para a } \\
\text { realização de parcerias com a } \\
\text { iniciativa privada } \\
\text { Lei de licitações limitando o } \\
\text { número de fornecedores } \\
\text { Falta de recursos para } \\
\text { investimento em infraestrutura } \\
\text { para atender os requisitos legais }\end{array}$ \\
\hline Tecnologia & $\begin{array}{l}\text { Disponibilidade de acesso a bases } \\
\text { de dados de qualidade para } \\
\text { realização de pesquisas } \\
\text { (Micromedex®, Up to Date®) } \\
\text { Oportunidade de se tornar local de } \\
\text { ensino (Hospital Escola) para } \\
\text { diferentes áreas, inclusive não } \\
\text { relacionadas a saúde } \\
\text { Tecnologia disponível no mercado } \\
\text { aumentando a oferta e diminuindo } \\
\text { custo }\end{array}$ & $\begin{array}{l}\text { Falta de contato efetivo com áreas } \\
\text { da universidade não ligadas } \\
\text { diretamente a saúde } \\
\text { Sistema informatizado e } \\
\text { equipamentos disponíveis na } \\
\text { Farmácia e no Hospital limitado } \\
\text { frente às tecnologias disponíveis } \\
\text { no mercado devido falta de } \\
\text { recursos para investimento }\end{array}$ \\
\hline
\end{tabular}

A Tabela 2 mostra as oportunidades expostas nas oficinas referente ao ambiente externo setorial ligadas aos componentes de estrutura organizacional, das agências reguladoras, dos fornecedores, dos clientes, da gestão do hospital, da comunicação e da tecnologia. Em relação a estrutura organizacional foram mencionadas como ameaças o quadro insuficiente de funcionários estimulado pelo programa de demissão voluntária, ausência de plano de carreira e falta de estímulo e financiamento para aprimoramento, treinamento e melhorias estruturais. Como oportunidade foi citada a questão de o organograma da Divisão de Farmácia estar diretamente ligado à superintendência do hospital colocando a farmácia em uma posição privilegiada com relação a tomada de decisões. Outra oportunidade citada foi a 
presença de docentes como colaboradores e o programa de residência existente na instituição. As agências reguladoras foram vistas como ameaça com relação a falta de canais de comunicação efetivos e legislações defasadas ou inespecíficas. Em contrapartida, foram colocadas como oportunidade com relação as exigências que permitem à divisão de farmácia pleitear melhorias de infraestrutura física, tecnológica e organizacional do setor. No quesito fornecedor não foram apontadas oportunidades pelos colaboradores que participaram das oficinas e os processos burocráticos para realização de compras e a dificuldade de puni-los diante do descumprimento dos contratos foram apresentados como pontos negativos.

A falta de visão dos outros profissionais do hospital com relação as atividades desenvolvidas pelos colaboradores da Divisão de Farmácia e que dificulta o ajuste de fluxos interprofissionais foi considerada uma ameaça no quesito clientes. Entretanto, a prática de visitas multidisciplinares, o corpo clínico fechado de médicos assistentes e as diversas comissões multidisciplinares foram considerados como oportunidades de melhoria na comunicação entre os diversos setores do hospital e, consequentemente, na melhoria dos processos. A falta de comunicação efetiva entre os diferentes profissionais atuantes no hospital foi uma problemática constante citada como ameaça em todas as oficinas problemática também encontrada por Cazagrande e Pontes ${ }^{12}$ em seu estudo realizado em uma central de abastecimento farmacêutico de um hospital público de médio porte na cidade de Niterói.

Tabela 2. Análise das oportunidades e ameaças do ambiente externo - setorial da Divisão de Farmácia do HU-USP

\section{Oportunidades}

Estrutura organizacional
Posição privilegiada da farmácia dentro do organograma do hospital proporcionando maior poder de decisão

Presença de colaboradores docentes e programa de residência propiciando atividades de ensino e pesquisa continuamente

\section{Ameaças}

Dificuldade de reposição do

quadro de funcionários

Ausência de planos de carreira e avaliações de desempenho

Falta de incentivo para aprimoramento e treinamento

Dificuldade em adaptar os processos internos às mudanças externas

Ineficácia dos canais de comunicação referentes aos recolhimentos dos medicamentos realizados no mercado e alternativas de substituição

Maior segurança, observação e divulgação de eventos adversos devido à classificação como hospital sentinela
Defasagem na legislação específica para fabricação e distribuição de medicamentos semelhantes e unitarização 
Processos burocráticos para realização de compras

\begin{tabular}{|c|c|c|}
\hline Clientes & $\begin{array}{l}\text { Visitas multidisciplinares propiciando o } \\
\text { conhecimento quanto a atuação das } \\
\text { diferentes equipes de saúde de } \\
\text { maneira integral com o paciente, assim } \\
\text { como da equipe de farmácia clínica } \\
\text { Corpo clínico de médicos assistentes } \\
\text { fixos, proporcionando facilidade de } \\
\text { atuação, vínculo e educação das } \\
\text { equipes médicas }\end{array}$ & $\begin{array}{l}\text { Pequeno entendimento dos } \\
\text { clientes quanto ao papel ampliado } \\
\text { das atividades da Divisão de } \\
\text { Farmácia } \\
\text { Dificuldade para alterações de } \\
\text { rotinas e fluxos envolvendo } \\
\text { diferentes equipes profissionais } \\
\text { Ausência de educação } \\
\text { continuada interdisciplinar para } \\
\text { melhoria dos processos }\end{array}$ \\
\hline $\begin{array}{l}\text { Gestão do } \\
\text { hospital }\end{array}$ & $\begin{array}{l}\text { Gestores com perspectivas de } \\
\text { atividades educativas e planos } \\
\text { interdisciplinares para a instituição }\end{array}$ & $\begin{array}{l}\text { Planos de ação do hospital } \\
\text { relacionados com projetos e } \\
\text { afinidades do gestor do momento } \\
\text { Morosidade para resolução de } \\
\text { problemas resultando em } \\
\text { processos de melhoria pouco } \\
\text { produtivos }\end{array}$ \\
\hline Comunicação & $\begin{array}{l}\text { Melhoria nos processos de } \\
\text { comunicação para otimizar os } \\
\text { processos assistenciais já existentes }\end{array}$ & $\begin{array}{l}\text { Comunicação ineficiente entre as } \\
\text { equipes trazendo dificuldades } \\
\text { para o desenvolvimento de } \\
\text { melhorias e aproveitamento dos } \\
\text { processos já existentes }\end{array}$ \\
\hline Tecnologia & & $\begin{array}{l}\text { Sistemas disponíveis não } \\
\text { atendem totalmente as demandas } \\
\text { de rastreabilidade dos } \\
\text { medicamentos }\end{array}$ \\
\hline
\end{tabular}


A Tabela 3 mostra os pontos fortes e fracos do ambiente interno da Divisão de Farmácia referente a gestão e aos recursos humanos, a estrutura organizacional, a tecnologia, a comunicação e ao ensino. Assim como demonstrado no estudo realizado no serviço de farmácia do Hospital Universitário da Universidade de Sergipe por Silvestre e colaboradores em $2017^{11}$, no quesito gestão e recursos humanos, foi citada como fraqueza a dificuldade de criar mecanismos para valorização do trabalho dos colaboradores e determinar com clareza as atribuições dos diferentes colaboradores baseados em seu nível de carreira. A baixa rotatividade dos funcionários foi citada como força devido ao conhecimento desenvolvido por estas pessoas com relação as atividades desenvolvidas na Divisão de Farmácia, porém também foi colocada como fraqueza por criar a possibilidade de comodismo e resistência à mudança. A dificuldade de comunicação entre profissionais de diferentes setores foi mencionada como fraqueza por alguns funcionários da Divisão de Farmácia do HU. Como ponto positivo foi citado o quadro de farmacêuticos constituídos de especialistas com amplo conhecimento em suas áreas o que pode proporcionar melhorias à Divisão. Referente a estrutura organizacional, o grupo colocou como fraqueza a falta de revisão periódica nos processos, rotinas e organização dos espaços físicos, assim como no estudo de Silvestre e colaboradores ${ }^{11}$ em que citam como fraqueza a dificuldade de implantação de fluxos e processos na Divisão de Farmácia. Como força foi citada o fato de se tratar de um hospital-escola o que possibilita a integração entre ensino e serviço. Com relação a tecnologia foi colocado como fraqueza a falta de informatização e robotização dos processos, considerado de extrema importância para segurança dos processos. Abreu e Machado em $2016^{13}$ também encontraram na carência de informatização um problema que gera a falta de rastreabilidade e controle de estoque em seu estudo realizado em uma unidade básica de saúde do Distrito Federal. Novamente problemas de comunicação foram citados diversas vezes, agora ressaltando a necessidade de canais de comunicação internos e de divulgação para os meios acadêmicos e de saúde dos trabalhos realizados no HU possibilitando maior visibilidade e importância da divisão de farmácia entre os diferentes setores da universidade. No quesito ensino foi trazido pelos participantes como ponto forte, principalmente residentes, a quantidade de preceptores por aluno possibilitando o desenvolvimento de atividade de ensino e pesquisa. Por outro lado, como fraqueza foi citada a dificuldade de manter programas de educação continuada entre os funcionários.

Tabela 3. Análise dos pontos fortes e fracos do ambiente interno da Divisão de Farmácia do HU-USP

\begin{tabular}{lll}
\hline & Forças & Fraquezas \\
\hline $\begin{array}{lll}\text { Gestão e } \\
\text { Hecursos }\end{array}$ & Quadro de funcionários especialistas & $\begin{array}{l}\text { Falta de mecanismos para criar } \\
\text { medidas de valorização aos }\end{array}$ \\
& $\begin{array}{l}\text { Capacitação técnica e baixa } \\
\text { rotatividade de funcionários }\end{array}$ & $\begin{array}{l}\text { colaboradores } \\
\text { Baixa rotatividade de funcionários o }\end{array}$ \\
\hline
\end{tabular}


que gera resistência a mudanças

por parte dos colaboradores

Dificuldade de comunicação entre

profissionais de diferentes setores

Inexistência de um plano de

qualidade laboral para os

funcionários

\begin{tabular}{ll}
\hline $\begin{array}{l}\text { Estrutura } \\
\text { Organizacional }\end{array}$ & $\begin{array}{l}\text { Hospital escola (assistência, ensino } \\
\text { pesquisa), possibilitando a integração } \\
\text { ensino-serviço }\end{array}$ \\
& $\begin{array}{l}\text { Todos os processos do ciclo da } \\
\text { assistência farmacêutica ocorrem } \\
\text { dentro do próprio Hospital }\end{array}$
\end{tabular}

Falta de revisão periódica dos processos para melhoria contínua e adequação de processos e escopo de atividades

Necessidade de revisão da organização dos espaços e investimento em infraestrutura

\begin{tabular}{|c|c|c|}
\hline Tecnologia & $\begin{array}{l}\text { Desenvolvimento de soluções práticas } \\
\text { frente as tecnologias limitadas } \\
\text { disponíveis }\end{array}$ & $\begin{array}{l}\text { Necessidade de aquisição e } \\
\text { melhorias nos sistemas } \\
\text { informatizados disponíveis }\end{array}$ \\
\hline Comunicação & $\begin{array}{l}\text { Divulgação do serviço prestado por } \\
\text { meio de apresentação de indicadores a } \\
\text { alta direção do hospital }\end{array}$ & $\begin{array}{l}\text { Ineficácia dos canais de } \\
\text { comunicação internos e com } \\
\text { clientes da farmácia }\end{array}$ \\
\hline & $\begin{array}{l}\text { Disponibilização de protocolos e } \\
\text { informações técnicas e científicas para } \\
\text { melhoria dos processos }\end{array}$ & $\begin{array}{l}\text { Ineficácia de divulgação e marketing } \\
\text { dos serviços realizados na Divisão } \\
\text { de Farmácia }\end{array}$ \\
\hline Ensino & $\begin{array}{l}\text { Estrutura proporciona disponibilidade } \\
\text { de } 1 \text { preceptor por aluno de cada ano } \\
\text { Iniciativas em } 2018 \text { para educação } \\
\text { interdisciplinar }\end{array}$ & $\begin{array}{l}\text { Dificuldade em manter treinamentos } \\
\text { e capacitações para os diferentes } \\
\text { grupos de colaboradores } \\
\text { Falta de programa de educação } \\
\text { continuada interdisciplinar } \\
\text { Estrutura gera restrições } \\
\text { na participação de auxiliares e } \\
\text { técnicos em reuniões científicas }\end{array}$ \\
\hline
\end{tabular}


Após coletadas as informações durante as oficinas e estruturadas em planilhas, foram realizados os cruzamentos em 4 dimensões: alavanca, limitações, defesa e problemas. O cruzamento entre pontos fortes do ambiente interno com as oportunidades encontradas no ambiente externo resultou na alavanca (Tabela 4).

Deste cruzamento pode-se sugerir algumas ações de melhoria para a divisão de farmácia, como por exemplo, o aproveitamento do quadro de funcionários experientes e especializado cujo conhecimento pode ser utilizado para otimizar os processos, o desenvolvimento de atividades de educação continuada e ampliação das atividades de ensino. Os farmacêuticos devem aproveitar a oportunidade de mudança da população e complexidade de pacientes que estão sendo atendidos e investir em atividades de interdisciplinaridade, aproveitando a disponibilidade de alunos para ampliar as atividades de ensino criando metas de incentivo e utilizando recursos de tecnologia interno como a intranet para divulgação dos manuais e protocolos resultantes dos trabalhos desenvolvidos durante a permanência no hospital.

Tabela 4. Dimensão Alavanca da Divisão de Farmácia do HU-USP (pontos fortes - ambiente interno versus oportunidades - ambiente externo)

\begin{tabular}{|c|c|c|c|c|}
\hline & $\begin{array}{l}\text { Gestão e } \\
\text { pessoal }\end{array}$ & $\begin{array}{l}\text { Tecnologia e } \\
\text { estrutura } \\
\text { organizacion } \\
\text { al }\end{array}$ & Comunicação & Ensino \\
\hline $\begin{array}{l}\text { Políticas da } \\
\text { universidad } \\
\text { e }\end{array}$ & & $\begin{array}{l}\text { A1: Propor } \\
\text { iniciativas de } \\
\text { pesquisa e } \\
\text { ensino } \\
\text { envolvendo } \\
\text { as mudanças } \\
\text { da população } \\
\text { atendida }\end{array}$ & $\begin{array}{l}\text { A1: Disponibilizar os } \\
\text { protocolos e } \\
\text { manuais } \\
\text { desenvolvidos pela } \\
\text { Divisão de Farmácia } \\
\text { como material de } \\
\text { ensino para as } \\
\text { diversas equipes }\end{array}$ & $\begin{array}{l}\text { A1: Aproveitar o } \\
\text { número de } \\
\text { preceptores } \\
\text { disponíveis para } \\
\text { aumentar as } \\
\text { atividades de } \\
\text { ensino e } \\
\text { pesquisa }\end{array}$ \\
\hline $\begin{array}{l}\text { Recursos } \\
\text { financeiros }\end{array}$ & $\begin{array}{l}\text { A1: Aproveitar o } \\
\text { potencial dos } \\
\text { farmacêuticos } \\
\text { especialistas } \\
\text { para rever os } \\
\text { processos de } \\
\text { programação e } \\
\text { aquisição de } \\
\text { medicamento } \\
\text { e otimizar os } \\
\text { recursos } \\
\text { empregados na } \\
\text { Divisão de } \\
\text { Farmácia }\end{array}$ & & & \\
\hline Social & $\begin{array}{l}\text { A1: Aproveitar o } \\
\text { quadro de } \\
\text { farmacêuticos } \\
\text { especialistas }\end{array}$ & $\begin{array}{l}\text { A1: Utilizar a } \\
\text { configuração } \\
\text { de hospital } \\
\text { escola para }\end{array}$ & & \\
\hline
\end{tabular}




\begin{tabular}{|c|c|c|}
\hline & $\begin{array}{l}\text { para desenvolver } \\
\text { mais pesquisas e } \\
\text { atividades de } \\
\text { ensino } \\
\text { interdisciplinares } \\
\text { envolvendo a } \\
\text { nova população } \\
\text { atendida }\end{array}$ & $\begin{array}{l}\text { difundir } \\
\text { atividades de } \\
\text { humanização } \\
\text { entre os } \\
\text { profissionais } \\
\text { residentes e } \\
\text { estagiários } \\
\text { A2: Incentivar } \\
\text { os estagiários } \\
\text { e residentes a } \\
\text { desenvolver } \\
\text { projetos de } \\
\text { pesquisa } \\
\text { interdisciplinar } \\
\text { es } \\
\text { envolvendo a } \\
\text { nova } \\
\text { população } \\
\text { atendida, } \\
\text { promovendo } \\
\text { maior } \\
\text { integração } \\
\text { ensino- } \\
\text { serviço } \\
\text { A3: Aproveita } \\
\text { r a } \\
\text { proximidade } \\
\text { física com os } \\
\text { locais onde } \\
\text { são } \\
\text { realizadas } \\
\text { todas as } \\
\text { etapas da } \\
\text { assistência } \\
\text { farmacêutica } \\
\text { para } \\
\text { realização } \\
\text { especificaçõe } \\
\text { s que } \\
\text { atendam } \\
\text { melhor as } \\
\text { necessidades } \\
\text { dos pacientes } \\
\text { atendidos }\end{array}$ \\
\hline Legal/SUS & & $\begin{array}{l}\text { A1: Servir-se } \\
\text { dos relatórios } \\
\text { emitidos pelos } \\
\text { órgãos legais, } \\
\text { assim como } \\
\text { de suas } \\
\text { exigências de } \\
\text { qualidade e } \\
\text { princípios } \\
\text { norteadores } \\
\text { do SUS para } \\
\text { solicitar } \\
\text { investimentos }\end{array}$ \\
\hline
\end{tabular}


para melhoria

de

infraestrutura

física

e tecnológica

\begin{tabular}{|c|c|}
\hline Tecnologia & $\begin{array}{l}\text { A1: Propor } \\
\text { iniciativas junto } \\
\text { às diferentes } \\
\text { áreas da } \\
\text { Universidade de } \\
\text { São Paulo, sendo } \\
\text { diretamente } \\
\text { relacionadas a sa } \\
\text { úde ou não } \\
\text { A2: Aproveitar as } \\
\text { bases de dados } \\
\text { disponibilizadas } \\
\text { pela } \\
\text { Universidade } \\
\text { para o } \\
\text { desenvolvimento } \\
\text { de pesquisas } \\
\text { consistentes }\end{array}$ \\
\hline
\end{tabular}

\section{Estrutura organizacio nal}

\author{
A1: Criar \\ metas de \\ incentivo para \\ que \\ estagiários e \\ residentes \\ desenvolvam \\ pesquisas \\ interdisciplinar \\ es \\ incentivando \\ a integração \\ ensino- \\ serviço
}

A2:

Aproveitar a posição

privilegiada

da Divisão de

Farmácia no

organograma

do HU-USP

para pleitear a

direção as

necessidades

da divisão de

farmácia

\section{A1: Criar e atualizar periodicamente os manuais e protocolos existentes com a melhor fonte de informação disponível}

A2: Utilização da intranet como forma de divulgação dos protocolos e manuais elaborados pela divisão
A1: Aproveitar a quantidade de preceptores por aluno para desenvolver atividades de ensino e pesquisa a partir de buscas nas bases de dados disponibilizadas pela universidade

\author{
A1: Unir a \\ disponibilidade de \\ colaboradores \\ docentes e 0 \\ número de \\ preceptores por \\ aluno para \\ desenvolver \\ atividades de \\ ensino e pesquisa \\ e ampliar \\ a intersdiciplinarid \\ ade
}

\section{Agências reguladoras}
A1: Melhorar a integração das informações geradas pela
A1: Utilizar os dados obtidos pelo grupo de farmacovigilância para o desenvolvimento e 


\begin{tabular}{|c|c|c|c|c|}
\hline & & $\begin{array}{l}\text { farmacovigilâ } \\
\text { ncia e dos } \\
\text { processos de } \\
\text { seleção e } \\
\text { aquisição }\end{array}$ & $\begin{array}{l}\text { aprimoramento dos } \\
\text { manuais e } \\
\text { protocolos da } \\
\text { Divisão de Farmácia }\end{array}$ & \\
\hline Clientes & $\begin{array}{l}\text { A1: Dispor do } \\
\text { conhecimento } \\
\text { dos } \\
\text { farmacêuticos } \\
\text { especialistas } \\
\text { para o } \\
\text { desenvolvimento } \\
\text { de atividades de } \\
\text { educação } \\
\text { continuada junto } \\
\text { ao corpo clínico }\end{array}$ & $\begin{array}{l}\text { A1: Corpo } \\
\text { clínico fixo de } \\
\text { assistentes } \\
\text { facilita a } \\
\text { difusão de } \\
\text { informações e } \\
\text { atividades de } \\
\text { ensino da } \\
\text { farmácia junto } \\
\text { aos } \\
\text { residentes da } \\
\text { equipe } \\
\text { médica }\end{array}$ & $\begin{array}{l}\text { A1: Utilizar manuais } \\
\text { e protocolos } \\
\text { disponíveis como } \\
\text { forma de } \\
\text { comunicação e fonte } \\
\text { de informação } \\
\text { junto à toda equipe } \\
\text { assistencial, } \\
\text { propiciando um } \\
\text { atendimento mais } \\
\text { seguro } \\
\text { A2: Aproveitar as } \\
\text { visitas } \\
\text { multidisciplinares } \\
\text { como meio de } \\
\text { difundir informações } \\
\text { e promover ensino }\end{array}$ & $\begin{array}{l}\text { A1: Aproveitar a } \\
\text { quantidade de } \\
\text { preceptores por } \\
\text { aluno para } \\
\text { desenvolver } \\
\text { atividades } \\
\text { multidisciplinares } \\
\text { e incentivar a } \\
\text { interdisciplinaridad } \\
\text { e junto as outras } \\
\text { equipes }\end{array}$ \\
\hline $\begin{array}{l}\text { Gestão do } \\
\text { hospital }\end{array}$ & $\begin{array}{l}\text { A1: Empregar o } \\
\text { conhecimento e } \\
\text { experiência dos } \\
\text { colaboradores e } \\
\text { especialistas } \\
\text { para desenvolver } \\
\text { e ampliar } \\
\text { atividades } \\
\text { educativas } \\
\text { interdisciplinares } \\
\text { apoiadas pelos } \\
\text { gestores do HU- } \\
\text { USP como as } \\
\text { oficinas de } \\
\text { comunicação }\end{array}$ & & $\begin{array}{l}\text { A1: Explorar o } \\
\text { incentivo por parte } \\
\text { da gestão do HU- } \\
\text { USP para } \\
\text { desenvolver } \\
\text { protocolos de } \\
\text { cuidados } \\
\text { interdisciplinares }\end{array}$ & $\begin{array}{l}\text { A1: Utilizar a } \\
\text { quantidade de } \\
\text { preceptores por } \\
\text { aluno para } \\
\text { expandir as } \\
\text { atividades } \\
\text { interdisciplinares } \\
\text { incentivadas pelos } \\
\text { gestores do } \\
\text { hospital, como as } \\
\text { oficinas de } \\
\text { comunicação e o } \\
\text { grupo de } \\
\text { atendimento ao } \\
\text { idoso frágil }\end{array}$ \\
\hline $\begin{array}{l}\text { Comunicaçã } \\
\text { o }\end{array}$ & & $\begin{array}{l}\text { A1: Criação } \\
\text { de } \\
\text { alternativas } \\
\text { de } \\
\text { comunicação } \\
\text { para suprir as } \\
\text { limitações } \\
\text { tecnológicas } \\
\text { de controle de } \\
\text { estoque } \\
\text { como, por } \\
\text { exemplo, o } \\
\text { Kanban }\end{array}$ & & $\begin{array}{l}\text { A1: Aproveitar as } \\
\text { iniciativas de } \\
\text { interdisciplinaridad } \\
\text { e para otimizar a } \\
\text { comunicação com } \\
\text { as diferentes } \\
\text { profissões e } \\
\text { consequentement } \\
\text { e os processos } \\
\text { assistências } \\
\text { interequipes }\end{array}$ \\
\hline
\end{tabular}


A Tabela 5 mostra a dimensão da defesa, onde podem-se observar quais pontos fortes internos podem minimizar as ameaças externas. Uma das ameaças apontadas durante as oficinas foi a falta de percepção do HU como unidade de ensino por outras unidades e neste ponto a presença no grupo de farmacêuticos especialistas e docentes representa um potencial para mudança por meio de maior divulgação dos trabalhos realizados por estes profissionais dentro da instituição ampliando o entendimento externo das atividades desenvolvidas pelo HU. Outras ameaças apontadas foram a crise econômica e financeira da universidade e o aumento da demanda de atendimento pelo SUS, situações que podem ser contornadas por meio da revisão de processos internos e criação de protocolos, já que a unidade tem como força possuir profissionais qualificados e estar inserida dentro da universidade em contato com outras unidades de ensino.

Tabela 5. Dimensão das defesas da Divisão de Farmácia do HU-USP (pontos fortes - ambiente interno versus ameaças - ambiente externo).

\begin{tabular}{|c|c|c|c|}
\hline & $\begin{aligned} \text { Gestão e pessoal Tecnologia e } \\
\text { estrutura } \\
\text { organizacional }\end{aligned}$ & Comunicação & Ensino \\
\hline $\begin{array}{l}\text { Políticas da } \\
\text { Universidade }\end{array}$ & $\begin{array}{l}\text { D1: Aproveitar o } \\
\text { quadro de } \\
\text { farmacêuticos } \\
\text { especialistas para } \\
\text { desenvolver } \\
\text { atividades de } \\
\text { ensino e } \\
\text { estabelecer metas } \\
\text { e publicações, a } \\
\text { fim de ganhar } \\
\text { visibilidade e } \\
\text { alterar a visão do } \\
\text { Hospital por } \\
\text { alguns setores da } \\
\text { Universidade } \\
\text { D2: Dispor do } \\
\text { conhecimento dos } \\
\text { farmacêuticos para } \\
\text { otimizar as } \\
\text { atividades e } \\
\text { minimizar os } \\
\text { efeitos da crise } \\
\text { econômica }\end{array}$ & $\begin{array}{l}\text { D1: Disponibilizar } \\
\text { os manuais e } \\
\text { protocolos } \\
\text { desenvolvidos na } \\
\text { Divisão de } \\
\text { Farmácia como } \\
\text { materiais de } \\
\text { ensino, divulgá- } \\
\text { los para outros } \\
\text { setores e para } \\
\text { outros serviços } \\
\text { futuramente }\end{array}$ & $\begin{array}{l}\text { D1: Aproveitar } \\
\text { quantidade de } \\
\text { preceptores para } \\
\text { estabelecer metas } \\
\text { e rotinas que } \\
\text { possibilitem o } \\
\text { desenvolvimento e } \\
\text { a divulgação das } \\
\text { experiências de } \\
\text { ensino e pesquisa } \\
\text { para diferentes } \\
\text { setores da } \\
\text { universidade }\end{array}$ \\
\hline $\begin{array}{l}\text { Recursos } \\
\text { financeiros }\end{array}$ & $\begin{array}{l}\text { D1: Utilização dos } \\
\text { conhecimentos } \\
\text { dos farmacêuticos } \\
\text { especialistas para } \\
\text { otimizar os } \\
\text { processos de }\end{array}$ & $\begin{array}{l}\text { D1; Criação de } \\
\text { protocolos que } \\
\text { visem o uso } \\
\text { racional de } \\
\text { medicamentos e } \\
\text { que promova o }\end{array}$ & \\
\hline
\end{tabular}




\begin{tabular}{|c|c|c|c|c|}
\hline & $\begin{array}{l}\text { gestão de estoque } \\
\text { e recursos } \\
\text { disponíveis } \\
\text { D2: Estabelecer } \\
\text { uma aproximação } \\
\text { dos farmacêuticos } \\
\text { da Divisão de } \\
\text { Farmácia junto aos } \\
\text { profissionais da } \\
\text { rede para } \\
\text { promover a } \\
\text { melhoria dos } \\
\text { fluxos de } \\
\text { referência e } \\
\text { contrarreferência }\end{array}$ & s & $\begin{array}{l}\text { não desperdício } \\
\text { de recursos }\end{array}$ & \\
\hline Social & & & $\begin{array}{l}\text { D1: Criação de } \\
\text { protocolos que } \\
\text { visem o uso } \\
\text { racional de } \\
\text { medicamentos } \\
\text { promovam o não } \\
\text { desperdício de } \\
\text { recursos }\end{array}$ & $\begin{array}{l}\text { D1: Utilizar os } \\
\text { preceptores } \\
\text { disponíveis para } \\
\text { desenvolver } \\
\text { projetos e criar } \\
\text { metas com a } \\
\text { finalidade de } \\
\text { consolidar o tripé } \\
\text { ensino, pesquisa e } \\
\text { assistência }\end{array}$ \\
\hline Tecnologia & & $\begin{array}{l}\text { D1: Criação de } \\
\text { alternativas que } \\
\text { tentem minimizar } \\
\text { as limitações dos } \\
\text { sistemas } \\
\text { informatizados } \\
\text { disponíveis no } \\
\text { hospital }\end{array}$ & $\begin{array}{l}\text { D1: Utilização da } \\
\text { intranet como } \\
\text { forma de } \\
\text { disponibilizar } \\
\text { informações, } \\
\text { protocolos e } \\
\text { manuais da } \\
\text { Divisão de } \\
\text { Farmácia }\end{array}$ & \\
\hline
\end{tabular}


As limitações da divisão correspondem ao cruzamento dos pontos fracos internos com as oportunidades oferecidas pelo ambiente externo, ou seja, neste ponto existe a dificuldade de desenvolvimento de ações de melhoria frente as fraquezas apresentadas. Neste ponto o ideal é desenvolver ações que anulem ou reduzam as limitações como implantações de ferramentas práticas para melhorias dos processos, manutenção da educação continuada dos colaboradores e da revisão continua e monitoramento dos processos internos com objetivo de manter modelos que garantam a segurança na utilização do medicamento e demonstrar a necessidade de cumprimento da legislação.

O último cruzamento resulta nos problemas da divisão após o cruzamento dos pontos fracos internos com as ameaças externas, ou seja, existe uma incapacidade do setor em enfrentar as ameaças ambientais externas. Neste ponto a falta de recursos financeiros tem grande impacto no cenário de hospitais públicos.

\section{CONCLUSÃO}

Pode-se observar ao final deste trabalho que o objetivo pretendido foi alcançado, uma vez que se contribuiu para o aprimoramento do planejamento estratégico dentro da divisão de farmácia por meio da análise situacional do ambiente externo e interno o que possibilitou uma reflexão entre os colaboradores referente as problemáticas e potencialidades do serviço. Os dados obtidos permitem que as próximas etapas do planejamento estratégico sejam realizadas com maior assertividade, pois estarão baseadas em uma visão realística dos potenciais e das limitações do serviço.

A próxima etapa consiste em priorizar quais alavancas resultantes da análise SWOT serão trabalhadas para que sejam definidos os objetivos e criados planos de ação e metas para que estes objetivos sejam mensurados e atingidos criando um fluxo de melhoria contínua com gestão participativa para o serviço.

\section{REFERÊNCIAS}

1. Silva JS. O mapeamento de processos organizacionais no setor público estudo de caso do escritório de processos da Agência Nacional de Vigilância Sanitária - ANVISA. Monografia (Graduação) - Universidade de Brasília, Brasília; 2014.

2. Souza DG. Metodologia de mapeamento para gestão de processos. Dissertação (Mestrado) - Programa de Pós Graduação em Engenharia de Produção, Universidade Federal do Rio Grande do Sul; 2014. 
3. Lima MBBPB. A gestão da qualidade e o redesenho de processos como modelo de desenvolvimento organizacional em hospitais públicos universitários: O caso do Hospital de Clínicas da UNICAMP. Dissertação (Mestrado Profissional) - Pós Graduação da Faculdade de Engenharia Mecânica, Universidade Estadual de Campinas; 2006.

4. Carpinetti LCR. Gestão da qualidade: conceitos e técnicas. $3^{a}$ ed. São Paulo: Atlas; 2016.

5. Valadares MCB. Planejamento Estratégico Empresarial. Rio de Janeiro: Qualitymark; 2002.

6. Torres MCS, Torres A, Serra F. Balanced scorecard. Rio de Janeiro: FGV; 2008.

7. Lobato DM, et al. Estratégia de empresas. $8^{\underline{a}}$ ed. Rio de Janeiro: FGV; 2008.

8. Cipriano SL. Gestão estratégica em farmácia hospitalar: aplicação prática de um modelo de gestão para qualidade. São Paulo: Atheneu; 2009.

9. Vasconcellos Filho P. Análise ambiental para o planejamento estratégico. Revista de Administração de Empresas 1979; 19:115-117.

10. Moyses Filho J, et al. Planejamento e gestão estratégica em organizações de saúde. $2^{\underline{a}}$ ed. Rio de Janeiro: Editora FGV; 2016. p. 160.

11. Silvestre $C$, et al. Análise situacional de um Hospital Universitário: um relato de experiência. Revista Brasileira de Farmácia Hospitalar e Serv. Público 2017; 8:18-25

12. Cazagrande GS, Pontes AT. Aplicação do planejamento estratégico situacional na central de abastecimento farmacêutico de um hospital público de médio porte. Sistemas \& Gestão 2018; 13(1): 25-35.

13. Abreu $\mathrm{CRC}$ et al. Planejamento estratégico situacional na farmácia de uma UBS em um município do entorno sul do Distrito Federal. Boletim informativo Geum 2016; 7(3):7-15.

Conflito de Interesses: os autores declararam não haver conflito de interesses.

\section{ANEXO 1}


Avaliação do ambiente externo - Macroambiente

Oportunidades

Ameaças

Política universidade

Recursos financeiros

Social

Legal/SUS

Tecnologia

Avaliação do ambiente externo - Ambiente setorial

Estrutura organizacional

Agências reguladoras

Fornecedores

Clientes

Gestão (do hospital)

Comunicação

Tecnologia

\section{Avaliação do ambiente interno}

Gestão e RH

Estrutura Organizacional

Tecnologia

Comunicação

Ensino 
Recebido: 09 de dezembro de 2019. Aceito: 09 de fevereiro de 2020

Correspondência: Ana Paula Callejo de Souza. E-mail: anapcs@hu.usp.br

Conflito de Interesses: os autores declararam não haver conflito de interesses.

(C) This is an Open Access article distributed under the terms of the Creative Commons Attribution License, which permits unrestricted use, distribution, and reproduction in any medium, provided the original work is properly cited 